\title{
ARGO - ALTERNATE-REALITY GOALSMITO E GAMIFICAÇÃO COMO RECURSO DA APRENDIZAGEM SIGNIFICATIVA NA EDUCAÇÃO EXECUTIVA
}

\author{
RIO DE JANEIRO/RJ ABRIL/2018 \\ Mary Kimiko Guimarães Murashima - FGV - mary.murashima@fgv.br \\ André Luiz Fialho Coutinho - FGV - andre.coutinho@fgv.br \\ Márcia de Medeiros Aguiar - FGV - marcia.aguiar@fgv.br \\ Tipo: Relato de Experiência Inovadora (EI) \\ Categoria: Métodos e Tecnologias \\ Setor Educacional: EDUCAÇÃO CORPORATIVA
}

\begin{abstract}
RESUMO
A partir da necessidade de desenvolvimento de novas estratégias de aprendizagem alinhadas às variações no perfil geracional dos alunos de MBA da Fundação Getulio Vargas, com o objetivo de prepará-los para as mudanças (em processo) no mercado de trabalho, a área de Soluções Educacionais (SOL) do Instituto de Desenvolvimento Educacional (IDE) da FGV desenvolveu uma metodologia de gamificação - Alternate Reality Goals (ARGo) -, com base no mito grego dos argonautas, cuja finalidade é fortalecer competências transversais que garantam a polivalência profissional nos novos mercados, a convivência participativa, a iniciativa, a criatividade e a qualidade do trabalho, além de potencializar o networking dos alunos dos diferentes cursos de MBA on-line oferecidos pela Instituição em diversas localidades do país. Este artigo visa divulgar a experiência da área com esse trabalho.
\end{abstract}

Palavras-chave: 1. Gamificação 2. ARG 3. Mito

AGRADECIMENTOS

NOSSOS AGRADECIMENTOS A TODOS OS ALUNOS, PROFESSORES, CONSULTORES, TUTORES E A TODA A EQUIPE DE PRODUÇÃO DA SOL/IDE, QUE TRILHARAM CONOSCO MARES NUNCA ANTES NAVEGADOS EM BUSCA DO NOSSO VELO DE OURO. 


\section{Introdução: começando por um jogo de palavras}

No processo de ensino e aprendizagem, nenhuma palavra é mais forte do que interação, já que o conhecimento se constrói nas interações do sujeito, integrado em um processo histórico, com o meio em que vive. Uma das formas de interagir, e consequentemente aprender, é por meio de games (jogos). Eis porque a ação de jogar - uma atividade física ou mental, organizada segundo regras que definem a vitória ou a derrota - é tão antiga como o próprio homem, que sempre manifestou uma tendência lúdica, isto é, um impulso para a diversão e para o enfrentamento de desafios, além da vontade de conhecer. Ou seja, o homem, que é sapiens, também é ludens.

Desse entendimento do sentido dos jogos em nossas vidas, surge a valorização de ações lúdicas ou gamificadas nas práticas educacionais. Muito mais facilmente do que se pensa, ações gamificadas ou mesmo jogos podem e devem ser criados pelo professor, pelos alunos ou, conjuntamente, pelo professor e pelos alunos. Games podem ser utilizados em atividades de todos os componentes curriculares com diferentes propostas, como forma de trabalhar diversos conteúdos; para integração da turma; para desenvolver espírito solidário e respeito mútuo; para desenvolver o espírito de grupo, onde todos têm um objetivo comum, bem como para fortalecer o senso crítico e a autonomia. Agora, contudo, incluem-se ainda no novo paradigma que o mercado de trabalho inscreve à nossa frente, ou seja, os games vierem para ficar e sua prática na educação executiva, pode, de fato, representar uma diferença no processo de aprendizado.

O primeiro passo é planejar, vale dizer, ser sapiens, o que significa delinear cenários, recursos, estratégias e regras, alinhando-os e adequando-os aos objetivos de aprendizagem a serem alcançados, à maturidade do grupo bem como aos conteúdos conceituais, procedimentais e atitudinais sobre os quais se alicerçam. O segundo passo é valorizar a criatividade, a inovação, e assumir o desafio de que problematizar pode ser uma ação tão necessária quanto divertida, ou seja, ser ludens, uma exigência dos novos tempos que demandam dos educadores cada vez mais "jogo de cintura", como veremos a seguir.

\section{Educação executiva: as apostas nas competências do futuro}

O Instituto do Futuro publicou, em 2011[1], um estudo sobre competências de trabalho fundamentais para 2020. Essas competências, que não são próprias de uma ou outra profissão em especial, mas que tornam possível que as pessoas atuem com efetividade, trabalhem bem umas com as outras, apresentem bom desempenho e atinjam seus 
objetivos, são as chamadas soft skills, que devem ser, cada vez mais, o foco das ações didáticas daqueles que trabalham com a educação executiva. Dentre elas, gostaríamos de destacar: sense-making, que é a capacidade de determinar o significado mais profundo do que está sendo expresso; inteligência social, porque o indivíduo deve ser capaz de se conectar com os outros de maneira profunda e direta; pensamento computacional enew-media literacy, porque o indivíduo deve ser capaz de traduzir grandes quantidades de dados em conceitos abstratos e compreender o raciocínio baseado em dados, dominando information, media, digital e virtual literacy; design mindset, que é a capacidade de representar bem como de desempenhar tarefas e processos de trabalho para alcance dos resultados desejados; virtual collaboration, pois, nesse novo mundo digital, é preciso que o indivíduo aprenda a trabalhar de forma produtiva, tenha compromisso e demonstre sua presença como membro de uma equipe virtual; pensamento inovador e adaptativo, pois se espera do indivíduo uma postura proativa de pensar e de apresentar soluções ou respostas para além daquilo que é traçado ou baseado em regras, desprendendo-se de verdades já formadas para pensar sobre novos contextos; cross-cultural competency, que é a competência da mobilidade em culturas transversais, e, por fim, gostaríamos de destacar a competência da transdisciplinaridade, que é a capacidade de compreender e articular conceitos de diversas disciplinas, pois, a cada dia, os assuntos estão mais relacionados e o profissional precisa ser capaz de transitar entre essas diferentes áreas de conhecimento sem barreiras.

Dadas essas competências, é notório compreender que os alunos deverão estar preparados para uma realidade diferente da que presenciamos após a faculdade. Eles serão desafiados em um mundo que muda de forma rápida e imersos nas tecnologias. Eles precisarão definir quais informações utilizar e em que momento. As barreiras territoriais foram ultrapassadas pela tecnologia e as demais barreiras, como a cultura e a linguagem, estão, a cada dia, tornando-se menos significativas.

Em meio a esses cenários, a sala de aula (ou o ambiente de aprendizagem) vista como o espaço (concreto ou virtual) da educação formal, onde ocorre a reconstrução de conhecimento, por meio das interações entre alunos, professores e conteúdos, também precisa mudar. Concebida como espaço de transmissão do conhecimento, passa a ser baseada, principalmente, no conceito de colaboração, em que: o sujeito precisa do contato com o outro para que o conhecimento possa ser reconstruído; o foco está no aluno e não mais no conteúdo ou no professor; o domínio de fontes teóricas desvalorizase, frente à capacidade de aplicá-las e a fala do docente deixa de ser voz reinante, promovendo o engajamento dos alunos, ou seja, as regras do jogo mudaram e é preciso reaprender a jogar. 


\section{Problematizando a realidade por meio da ficção: tudo não passa de um jogo?}

No livro 2020 Workplace: how innovative companies atract, develop and keep tomorrow's employees today, de Jeanne Meister e Karie Willyerd, as autoras entrevistaram milhares de executivos e trabalhadores das quatro gerações (veteranos, baby boomers, geração $\mathrm{X}$ e $\mathrm{Y}$ ) presentes no mercado de trabalho, com o intuito de definir as características do mercado e dos profissionais que nele atuarão nos próximos anos. Das 20 características listadas pelas autoras - e que estão profundamente relacionadas às competências já elencadas anteriormente -, uma delas interessa-nos particularmente e se refere à utilização de videogames, simulações e alternate-reality games no treinamento corporativo para o desenvolvimento das competências de estratégia, liderança, interação e pensamento crítico.

Nos últimos anos, os chamados jogos de negócios ganharam espaço nos ambientes educacionais, alavancando o desenvolvimento de diferentes habilidades específicas em situações diversas do mundo do trabalho. O grande problema da maioria desses serious games, contudo, é que eles se apresentam muito mais como "simuladores" e muito menos como "jogos", deixando para o segundo plano o potencial lúdico e a criatividade.

Exatamente por acreditarem que a diversão e o prazer podem ser aliados eficazes do processo de aprendizagem, várias empresas no mundo têm incentivado a participação de seus colaboradores em MMORPGs - Massivily Multiplayer Online Role-Playing Games -, também conhecidos como MMOs, visando ao desenvolvimento de competências estratégicas para diferentes tipos de negócios. Os MMOs são jogos em que os participantes assumem os papéis dos personagens (por meio de avatares) em um cenário fictício, atuando em uma narrativa e tomando decisões de acordo com um sistema formal de regras, competindo entre si. World of Warcraft[2], um jogo nessa linha, por exemplo, recentemente adaptado para as telas do cinema, possui mais de uma dezena de milhões de pessoas inscritas por todo o mundo.

De modo semelhante, ARGs - Alternate-Reality Games - também estão sendo usados por muitas empresas para simular cenários que mimetizam, no espaço on-line, situações possíveis de sua própria realidade. Os ARGs são jogos crossmidiáticos (que se utilizam de websites e redes sociais, além de outras mídias) que mesclam cenários do mundo real e virtual, fomentando experiências colaborativas que se estruturam em torno da resolução de desafios e mensagens criptografadas, visando decifrar enigmas e solucionar problemas. World Without Oi[3] é um exemplo. O jogo partiu da seguinte situação: um mundo em que os EUA foram cortados do mercado de importação de petróleo. Assim, no jogo, os participantes utilizaram diferentes tipos de mídia - blogs, 
vídeos, e-mails e audioclipes - para descrever os impactos da crise, o que fazer nessa situação e as implicações do uso da energia em nossa cultura e sociedade.

No Brasil, os MMOs desenvolvidos para plataformas como X-BOX, PS4 e PCs esbanjam tecnologia e são campeões de venda com fins de diversão. Já os ARGs exploram muito mais a criatividade e o trabalho colaborativo nas redes sociais, utilizando poucos recursos de desenvolvimento tecnológico e são muito mais usados, no Brasil, na área de marketing.

\section{Abrindo o jogo: conhecendo o ARGo}

Buscando continuamente criar novas estratégias de aprendizagem, a área de Soluções Educacionais (SOL) do Instituto de Desenvolvimento Educacional (IDE) da FGV, desenvolveu uma metodologia de gamificação com o objetivo de preparar seus alunos de MBA on-line para as mudanças (em processo) no mercado de trabalho.

O desenvolvimento de competências técnicas específicas já era um objetivo atendido pelas disciplinas ofertadas. Contudo, além delas, os futuros egressos precisavam desenvolver competências transversais que garantissem a polivalência profissional demandada pelos mercados nos próximos 10 anos, como convivência participativa, iniciativa, criatividade, resiliência, tomada de decisão de forma ética, adaptabilidade às mudanças, uso eficaz da comunicação, além de domínio de information, virtual e social media literacy.

Com o fim de desenvolver essas competências transversais e potencializar o networking dos alunos de todos os cursos, espalhados pelo país, os diferentes MBAs on-line passaram a contar, a partir de 2016, com um jogo desenvolvido em ambiente customizado do LMS da instituição, o eClass FGV, chamado de ARGo - Alternate Reality Goals - Space.

O ARGo Space é um espaço de interação e colaboração, mas também de disputa entre equipes, visando à resolução de problemas apresentados na forma de desafios e mistérios, desenvolvidos com base na metodologia dos MMOs e dos ARGs. A proposta é motivar os alunos, divididos em equipes multidisciplinares, por meio de uma narrativa central (front story) e de uma narrativa secundária (back story) que servirão como fios condutores para a solução de problemas, a aplicar os conhecimentos adquiridos e exercitar soft skills em situações possíveis de ocorrer no mundo real, ora colaborando, ora competindo para o alcance das metas propostas. 
A front story alicerça-se sobre a seguinte narrativa: uma empresa multinacional da área de pesquisa bioquímica recém-chegada ao Brasil - Argo Menthor -, partindo do entendimento de seu CEO de que empresas inovadoras e focadas em resultado têm preferência pela contratação de times de trainees à de talentos individuais e cada vez mais reconhecem as vantagens de se manter um time de trabalho em que cada um conhece os pontos fortes e fracos uns dos outros, abre processo de seleção para contratação, com inúmeras vantagens, de uma equipe multidisciplinar de trabalhos que irá conduzir processos radicais de mudança na organização, no projeto denominado Argonáutica. A Argo Menthor selecionou a FGV como parceira para contratar, dentre os alunos de seus MBAs on-line, a equipe que assumirá o projeto, ou seja, a equipe vencedora do ARGo.

É a back story, contudo, que traz os bastidores da Argo Menthor e a narrativa de um grande mistério que deverá ser desvendado pelas equipes, por meio do acesso contínuo a pistas que despertam a curiosidade dos participantes e os envolvem na resolução de outros problemas da empresa. Nesse sentido, o ARGo tem todos os elementos das narrativas de mistério clássicas: um board dividido, uma agenda oculta, uma descoberta espetacular na área bioquímica, uma fórmula desaparecida e muito mais.

O ARGo Space simula o espaço de recrutamento e seleção da Argo Menthor. Trata-se de três fases de desafios/mistérios que transcorrem simultaneamente às disciplinas regulares dos cursos. Cada tutor acompanha até 15 equipes multidisciplinares de 6 participantes, formadas com alunos dos quatro MBAs online oferecidos simultaneamente pela FGV: Gerenciamento de Projetos, Gestão Empresarial, Gestão Financeira e Direito Empresarial, originários de nove diferentes cidades[4].

No eClass FGV, foram criados espaços de interação entre e intraequipes, além de uma área de rankeamento, um diário de bordo e um arsenal de pistas, nos quais os participantes têm acesso a diferentes materiais audiovisuais. Nas redes sociais e na web, também foram criados sites e blogs fictícios, com mensagens e perfis - reais e ficcionais - para investigação.

As equipes podem apresentar bonificações que agregam pontuações específicas em diferentes momentos do jogo e as regras de pontuação visam a refletir o maior ou o menor alcance das competências demandadas em cada desafio.

\section{O mito e o game: o que está em jogo}

Outro diferencial do ARGo é a matriz mítica sobre a qual se estrutura o jogo. Todos os 
personagens, as mecânicas, os mistérios e as narrativas do ARGo tomam por base o mito grego dos argonautas, que foi transformado em poema épico por Apolônio de Rodes, em 250 a.C. - A Argonáutica. Mitos são atemporais e fornecem releituras inconscientes sobre angústias e medos que precisam ser apaziguados, respondendo a perguntas para as quais não encontramos respostas racionais e, nesse traçado, incentivam comportamentos modelares, fornecendo um sentido para o mundo.

Nesse sentido, a viagem de Jasão e dos mais de 50 heróis que partiram na nau Argo em busca do velocino de ouro simboliza a luta contra a banalização, em favor da verdade e da racionalidade, por meio da colaboração - valores que se coadunam aos do objetivo específico do jogo. Assim, por meio das referências ao mito, a metodologia de gamificação proposta encontrou a estratégia para não apenas fomentar o desenvolvimento de soft skills que serão a tônica dos próximos anos mas também de fomentar habilidades e valores que são atemporais e distintivos de posições de liderança em qualquer mercado de trabalho.

Além de Jason Higgins (CEO da Argo Menthor), nome escolhido como referência a Jasão, líder da expedição da Argo, os principais personagens do game possuem nomes e papéis no jogo relacionados aos heróis do mito, dentre eles: Michael Fineas (Presidente do Conselho Diretor); John Pelias (Conselheiro); Robert Amico (Conselheiro); Liz Circe (Pesquisadora-Chefe) e Amy Dea, (Pesquisadora). Compreender, pois, essa relação é o ponto de partida para que os participantes do ARGo possam decifrar os enigmas propostos e completar os desafios.

Ademais, durante todo o jogo, os participantes também são acompanhados por um tutor que, além da função de gerenciamento do game, avalia e pontua as tarefas e desafios, atuando sob diferentes avatares, dentre os quais se destacam: o de Nicholas Apoloni, gestor da Argo Menthor responsável pelo coaching das equipes no processo de recrutamento e Glória Calíope, assistente de Nicholas, que cria com os participantes uma interface mais empática e pessoal que a do recrutador, verdadeira musa inspiradora do jogo. Em cada um dos desafios propostos, o tutor também assume o avatar da Pitonisa, fornecendo pistas e orientações na forma de enigmas às equipes, quase sempre relacionadas a elementos do mito dos argonautas para levá-los à solução dos mistérios.

Cada uma das equipes toma ainda o nome de um dos heróis que participaram da viagem mítica da nau Argo, o que lhes acarreta bônus e ônus imputados pela Pitonisa em função do nome escolhido ao longo do jogo, donde a necessidade de os participantes realizarem diferentes pesquisas no processo de seleção do nome de cada 
equipe na fase inicial do jogo.

As diferentes passagens da viagem do Argonautas, com seus perigos e implicações, são ainda metaforicamente representadas nos desafios que são propostos aos participantes do jogo, que, tal qual os míticos argonautas, seguem sua viagem em busca de um também metafórico velocino de ouro. Nesse sentido, pode-se dizer que o ARGo explora a dimensão narrativa do mito para trazer de sua dimensão pedagógica os valores atemporais e universais que tão bem dialogam com as soft skills que o jogo procura exercitar em seus participantes: liderança, resiliência, trabalho em equipe, persistência - habilidades e valores demandados fortemente pelos mercados do futuro, como já apontamos, mas que sempre estiveram presentes como valores a serem perseguidos pela humanidade.

\section{O primeiro tempo de jogo: resultado e lições aprendidas}

A primeira oferta do ARGo contou com a participação de 124 alunos inscritos, distribuídos em 20 equipes. Atualmente, a duração do jogo é de 13 semanas e, apesar de a participação no ARGo não ser obrigatória, a avaliação dos participantes tem sido bastante positiva e seus depoimentos falam por si só:

Participante A:“Jogo extremamente proveitoso, especialmente para as equipes que permaneceram até o final. Fizemos novas amizades, aprendemos o conceito de holística, onde as partes de um todo, quando juntas, conseguem ser maiores que 0 próprio todo. Espero que continuemos a ter propostas assim na FGV. Aprender a superar desafios é essencial. "Calm seas never made good sailors".

Participante B:"Valor agregado imenso. Aprendemos a trabalhar em equipe a distância, planejar o tempo, trabalhar sob pressão. Cada desafio propôs um tema interessante que teve que ser estudado a fundo para embasar nossas propostas. Ótima experiência".

Participante C:Apesar da carga adicional de trabalho, para resolver mistérios e desafios, e pelo trabalho desenvolvido em equipe, considero que a participação nesta aventura agregou muito valor ao meu desenvolvimento pessoal".

Participante D:"Excelente, tanto para ajudar a trabalhar com diversidades como a distância. Foi um trabalho inusitado".

De modo geral, $85,7 \%$ dos participantes consideraram excelente a possibilidade de se relacionar com colegas de outros cursos e de outras cidades, competindo com e em 
equipes multidisciplinares e multirregionais, enquanto 14,3\% consideraram a experiência boa. As estratégias das equipes para interagir variaram bastante. As equipes com melhores resultados mantiveram contato diário, por meio de vários canais, como Whatsapp, Hangout, e-mail, telefone e até mesmo presencialmente (uma equipe optou por realizar a prova presencial obrigatória das disciplinas no Rio de Janeiro para interagir com os colegas de equipe).

O que se pôde verificar é que, se, por um lado, a narrativa do game impelia os argonautas a tomar decisões de acordo com as regras estabelecidas para poder competir com as equipes participantes, por outro, eles foram levados a ter experiências colaborativas, decifrando enigmas para chegar à resolução do mistério proposto.

O balanço do trabalho realizado mostrou que o ARGo favoreceu a interação e desenvolveu novos conceitos, apontando as dificuldades em se manter integrada uma equipe virtual mas também comprovando que a viagem valeu a pena. A bordo dessa nau, real e fictício se misturaram e todos contribuíram para que pudéssemos trilhar mares nunca antes navegados.

Agora, vamos continuamente ajustar a rota e nos preparar para os argonautas que virão. Nesse sentido, uma nova versão do ARGo - o Odyssey -, com base na Odisseia de Homero, encontra-se em fase de produção, dessa vez com foco nos alunos dos MBAs presenciais da FGV, que se encontram em mais de 130 cidades por todo o país... O jogo, na verdade, apenas começou.

\section{Bibliografia}

1. APOLÓNIO DE RODES. A Argonáutica. Sintra: Europa-América, 1989. [Clássicos].

2. BRANDÃO, Junito de Souza. Mitologia grega, v. I, 5 ed. Petrópolis: Vozes, 1989.

3. COSTA, R. Por um novo conceito de comunidade: redes sociais, comunidades pessoais, inteligência coletiva. Interface - Comunicação, Saúde, Educação, v. 9, n. 17, p. 235-48, mar/ago 2005.

4. DAVIES, Ana; FIDLER, Devin; GORBIS, Marina. Future wokskills 2020. Palo Alto: Institute for the Future for the University of Phoenix Research Institute. 2011. Disponivel em: http://www.iftf.org/futureworkskills/. Acesso em abr. 2018.

5. KAPP, Karl M. The gamification of learning and instruction: game-based methods and 
strategies for training and education. San Francisco: Pfeiffer, 2012.

6. Mc CRINDLE, M. The $A B C$ of $X Y Z$ : understanding the global generations. $3^{\text {rd }}$ ed. Australia: McCrindle Research, 2014.

7. MEISTER, J; WILLYERD, K. The 2020 workplace: how innovative companies attract, develop and keep tomorrow's employees today. New York: Harper-Collins. 2010.

8. PÉREZ, M. I.; BARROS, D. M. V.; SÁNCHEZ, I. O. Diretrizes para uma metodologia de alfabetização digital na modalidade virtual. Disponível em: < http://virtualeduca.info/zaragoza08/ponencias/233/resumen\%20virtualeduca2008.doc> Acesso em: set. 2017.

9. PRENSKY, M. Digital Natives, Digital Immigrants. On the Horizon, October 2001, 9(5) NCB University Press, 2001.

10. Aprendizagem baseada em jogos digitais. Trad. de Eric Yamagute. São Paulo: Senac, 2012.

11. TAPSCOTT, D. Grown up digital: how the net generation is changing your world. New York: McGraw-Hill, 2009.

12. VIANNA, Ysmar et alii. Gamification, Inc.: como reinventar empresas a partir de jogos. Rio de Janeiro: MJV Press, 2013.

13. VYGOTSKY, L. S. A formação social da mente. São Paulo: Martins Fontes, 1987.

[1] DAVIES, A. et alii. Future wokskills 2020, 2011.

[2] Disponível em: https://worldofwarcraft.com/pt-br/. Acesso em: jan. 2018.

[3] Disponível em: http://writerguy.com/wwo/metahome.htm. Acesso em: jan. 2018.

[4] Para assistir ao teaser do ARGo, acesse: http://ead4.fgv.br/recursos/ARGo/videos/teaser/argo teaser.html. 